\title{
The role of IFN- $\gamma$ and IL-4 in gastric mucosa inflammation associated with Helicobacter heilmannii type 1 infection
}

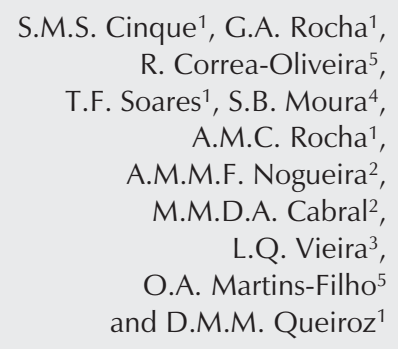

\author{
${ }^{1}$ Laboratório de Pesquisa em Bacteriologia, ${ }^{2}$ Departamento de Patologia, \\ Faculdade de Medicina, ${ }^{3}$ Departamento de Bioquímica e Imunologia, \\ ${ }^{4}$ Departamento de Microbiologia, Instituto de Ciências Biológicas, \\ Universidade Federal de Minas Gerais, Belo Horizonte, MG, Brasil \\ ${ }^{5}$ Cento de Pesquisa Renê Rachou, Fundação Osvaldo Cruz, Belo Horizonte, \\ MG, Brasil
}

\section{Correspondence}

D.M.M. Queiroz

Laboratório de Pesquisa em

Bacteriologia

Faculdade de Medicina, UFMG

Av. Alfredo Balena, 190, Sala 4026

30130-100 Belo Horizonte, MG

Brasil

Fax: +55-31-3274-2767

E-mail: dqueiroz@medicina.ufmg.br

Research supported by CNPq, CAPES, FIOCRUZ, and FAPEMIG

Received April 26, 2005 Accepted September 30, 2005

\begin{abstract}
Although Helicobacter heilmannii infection is less common than $H$. pylori infection in humans, it is considered to be of medical importance because of its association with gastritis, gastric ulcer, carcinoma, and mucosa-associated lymphoid tissue lymphoma of the stomach. However, there have been no studies evaluating the role of the Th cell response in $\mathrm{H}$. heilmannii gastric infection. We evaluated the participation of pro-inflammatory and anti-inflammatory cytokines, IFN- $\gamma$ and IL-4, in H. heilmannii gastric infection in genetically IFN- $\gamma$ - or IL4-deficient mice. The serum IFN- $\gamma$ and IL-4 concentrations were determined by ELISA. The gastric polymorphonuclear infiltrate was higher $(\mathrm{P}=0.007)$ in $H$. heilmannii-positive than in H. heilmanniinegative wild-type (WT) C57BL/6 mice, whereas no significant inflammation was demonstrable in the stomach of $H$. heilmannii-positive IFN- $\gamma^{-/-}$C57BL/6 mice. The degree of gastric inflammatory cells, especially in oxyntic mucosa, was also higher $(\mathrm{P}=0.007)$ in infected IL-4 ${ }^{-/-}$than in WT BALB/c mice. Serum IFN- $\gamma$ levels were significantly higher in IL-4- ${ }^{-/-}$than in WT BALB/c mice, independently of $H$. heilmannii-positive or -negative status. Although no difference in serum IFN- $\gamma$ levels was seen between $H$. heilmannii-positive (11.3 \pm $3.07 \mathrm{pg} / \mathrm{mL}$, mean $\pm \mathrm{SD})$ and -negative $(11.07 \pm 3.5 \mathrm{pg} / \mathrm{mL}) \mathrm{WT}$ $\mathrm{BALB} / \mathrm{c}$ mice, in the group of IL-4-/- animals, the serum concentration of IFN- $\gamma$ was significantly higher in the infected ones $(38.16 \pm 10.5 \mathrm{pg} /$ $\mathrm{mL}, \mathrm{P}=0.04)$. In contrast, serum IL-4 levels were significantly decreased in $H$. heilmannii-positive $(\mathrm{N}=10)$ WT BALB/c animals compared to the negative $(\mathrm{N}=10)$ animals. In conclusion, H. heilmannii infection induces a predominantly Th1 immune response, with IFN- $\gamma$ playing a central role in gastric inflammation.
\end{abstract}

Key words

- Helicobacter heilmannii

- Gastric mucosa

inflammation

- IFN- $\gamma^{-/-}$mice

- IL-4 ${ }^{-/-}$mice 


\section{Introduction}

Helicobacter pylori infects the gastric mucosa of half the world's population and the infection is considered to be an important factor in the pathogenesis of peptic ulcer $(1,2)$, distal gastric carcinoma (3) and mucosa-associated lymphoid tissue lymphoma (4). The reason why most infected subjects remain asymptomatic whereas only a few develop the related diseases is controversial. Besides environmental and bacterial virulence factors, differences in the host genetics may influence the type of tissue inflammatory reaction and subsequently the outcome of infection.

Following contact with antigen-presenting cells, T cells can develop into either Th1 or Th2 cells. Th1 cells produce the proinflammatory cytokines interferon- $\gamma$ (IFN$\gamma)$ and tumor necrosis factor- $\alpha$ that activate macrophages. Th2 clones synthesize IL-4 and IL-5, with consequent maturation of plasma cells and, ultimately, the production of immunoglobulins. Th1 and Th2 cells also cross-regulate each other, whereas IFN- $\gamma$ down-regulates the production of Th2 cytokines and IL-4 can regulate the Th1 pathway (5). Animal models such as $H$. pylori and $H$. felis infection in knockout mice deficient for specific cytokines have been used to clarify the immune response in Helicobacter infection (6-9). Data have shown that, in contrast to extracellular organisms such as helminths and many bacteria, the immune response to $H$. pylori is predominantly Th1 $(4,10,11)$.

In addition to $H$. pylori, another gastric spiral bacterium, $H$. heilmannii, has been demonstrated in the gastric mucosa of human beings (12-14). Although $H$. heilmannii infection is rare in humans, it is considered to be of medical importance because of its association with gastritis, gastric ulcer, carcinoma, and mucosa-associated lymphoid tissue lymphoma (15-18). In contrast to $H$. pylori infection, $H$. heilmannii more frequently colonizes the antral gastric mucosa.
Furthermore, the gastritis scores, based on the degree of polymorphonuclear (PMN) and mononuclear $(\mathrm{MN})$ cells, are lower in the gastric mucosa of H. heilmannii-positive patients than in the mucosa of $H$. pyloripositive patients $(14,16)$. The reason for these differences may be associated with the host's response to distinct Helicobacter species that may have different strategies for colonization and persistence in the gastric mucosa. Studies that evaluate cell-mediated responses in H. heilmannii infection would be of great value to explain why $H$. heilmannii induces a more modulated inflammatory response in the host.

H. heilmannii infection is considered to be a zoonosis and swine seem to be the most important reservoir of $H$. heilmannii for humans (19). In the pig, the infection is associated not only with gastritis, but also with pre-ulcerous lesions and ulcer of the pars esophagea $(20,21)$. Although the bacterium has not been cultured in vitro, oral inoculation of mice and rats with $H$. heilmanniipositive mucus of pig stomach results in $100 \%$ gastric infection that also leads to chronic gastritis (22-24). Based on comparative $16 \mathrm{~S}$ rDNA data, the sequence of the spiral porcine bacterium was shown to be identical to that of $H$. heilmannii type 1 $(21,25)$.

Since, to the best of our knowledge, there are no studies evaluating the role of Th immune response in the H. heilmannii gastric infection, we investigated the participation of pro-inflammatory and anti-inflammatory cytokines, IFN- $\gamma$ and IL-4, in the gastric infection by $H$. heilmannii type 1 in mice genetically deficient for IFN- $\gamma$ or IL-4.

\section{Material and Methods}

\section{Animals}

Groups of 10 Helicobacter-free female mice (7-8 weeks old) were studied: wild type (WT) and knockout $\left({ }^{-/}\right)$for IFN- $\gamma$ C57BL/6 
mice, whose genetic background is prone to a predominantly Th1 response, and WT and knockout for IL-4 BALB/c mice whose genetic background is prone to a predominantly $\mathrm{Th} 2$ response $(26,27)$.

The WT C57BL/6 and BALB/c mice were kindly provided by Oswaldo Cruz Institute (Rio de Janeiro, RJ, Brazil). IFN- $\gamma^{-/-}$ C57BL/6 mice were obtained from the Laboratory of Gnotobiology, Department of Biochemistry and Immunology, ICB/UFMG, Brazil, bred from pairs purchased from Jackson Laboratories (B6.129S7-ifng ${ }^{\text {tm } / T s}$, ME/USA). IL-4 ${ }^{-/}$BALB/c mice were obtained from breeding pairs kindly provided by Dr. Nancy Noben-Trauth (NIH, Bethesda, MD, USA). The animals were bred in microisolators and kept under specific pathogen-free conditions according to the international guidelines for laboratory animal care.

\section{Helicobacter heilmannii inoculum}

Since $H$. heilmannii is a non-cultivable bacterium, mucus from a pig stomach had to be used as an inoculum of the microorganism. The stomach of a pig naturally infected with $H$. heilmannii and the stomach of a pig not infected with the bacterium were used. Mucus was obtained from scrapings of the whole area of the antral region of the $H$. heilmannii-positive or -negative stomach.

Mucus positive for H. heilmannii showed a rapidly positive result for the urease test, presented many tightly spiraled bacteria in carbolfuchsin-stained smears and was PCR positive for $H$. heilmannii type 1 (24). Bacterial viability was assayed by checking motility by phase contrast microscopy. Mucus negative for $H$. heilmannii had a negative urease test, did not reveal any spiral bacteria in the smears and was PCR negative for the genus Helicobacter (28).

One part of the mucus was vigorously homogenized in three parts of $0.85 \%(\mathrm{w} / \mathrm{v})$ saline in a vortex blender and then used for inoculation.

\section{Experimental design}

All animal procedures were carried out in accordance with the National Institute of Health Guide for the Care and Use of Laboratory Animals.

Groups of 10 mice of each strain (WT and IFN- $\gamma^{-1-}$ C57BL/6, WT and IL-4 ${ }^{-/}$ $\mathrm{BALB} / \mathrm{c}$ mice) were inoculated orally with $0.5 \mathrm{~mL}$ of the $H$. heilmannii-positive mucus homogenate, corresponding to an inoculum of approximately $10^{5}$ bacteria $/ \mathrm{mL}$. Four other groups, also consisting of 10 mice of each strain, were inoculated orally with $0.5 \mathrm{~mL}$ of the $H$. heilmannii-negative mucus homogenate. All $H$. heilmannii-positive and -negative mice were inoculated on the same day with the gastric mucus homogenate from the same $H$. heilmannii-positive and -negative pig stomach, respectively. The animals were kept in separate cages and had free access to an autoclaved pelleted diet and sterile water during the experimental period.

The animals were sacrificed 4 weeks after inoculation under ether anesthesia and blood was obtained by heart section. Blood samples were centrifuged and the sera stored at $-4^{\circ} \mathrm{C}$. Fragments of the antral and oxyntic gastric mucosa of each animal were obtained for microbiological and histological studies.

\section{Microbiology}

The specimens were inserted into $2 \%$ Christensen's urea agar for the urease test and examined within $24 \mathrm{~h}$ to detect preformed urease. For carbolfuchsin-stained smears, specimens were smeared onto a glass slide, heat fixed, stained with $40 \%$ carbolfuchsin for $5 \mathrm{~min}$ and examined under an oil immersion lens for the presence of tightly spiraled bacteria (29). Bacterial viability was determined by observing motility by phase contrast microscopy of fresh gastric mucus preparations.

Specimens for culture were plated onto 
Belo Horizonte medium (30) and Skirrow's medium (30) and incubated at $37^{\circ} \mathrm{C}$ under micro-aerobic conditions obtained by a gas generation system (Anaerocult C, Merck, Darmstadt, Germany) for up to 10 days. Colonies with the macroscopic aspect of Helicobacter were tested for catalase, cytochrome-oxidase and urease and then Gram stained.

DNA from mucosal fragments was extracted with a QIAamp DNA minikit (Qiagen GmbH, Hilden, Germany) and 16S rRNA gene was amplified by nested PCR using primer sets specific for Helicobacter genus according to Oliveira et al. (28). For the detection of $H$. heilmannii type 1 species, 16S rRNA cistrons were amplified with primers chosen on the basis of the 16S rRNA gene sequence of $H$. heilmannii type 1 as described by Duval-Araujo et al. (24).

\section{Histology}

Histological sections of the antral and oxyntic mucosa were stained with hematoxylin-eosin and examined by two pathologists who were unaware of their origin. The levels of MN and PMN cells in the antral and oxyntic mucosa were scored as absent (0), mild (1), moderate (2), or marked (3), according to the modified Sydney system for human gastritis classification (31).

Since $H$. heilmannii is a non-cultivable organism, histological sections were also stained with carbolfuchsin (29) and used for the evaluation of bacterial density. Ten adjacent areas of the mucosa were evaluated by counting the number of bacteria inside the glands.

\section{Serum IL-4 and IFN- $\boldsymbol{\gamma}$ concentrations}

The serum concentrations of IFN- $\gamma$ (sensitivity $<5 \mathrm{pg} / \mathrm{mL}$ ) and IL-4 (sensitivity $<1$ $\mathrm{pg} / \mathrm{mL}$ ) were measured using a commercial ELISA (Biosource International, Camarillo, CA, USA) according to manufacturer rec- ommendations. The concentrations of IL-4 and IFN- $\gamma$ are reported as means \pm SD for 10 mice in each group.

\section{Statistical analysis}

The results of inflammatory cell infiltration in the gastric mucosa are reported as median percent values and analyzed by the two-tailed Mann-Whitney U-test. The mean values of IFN- $\gamma$ and IL- 4 concentrations were compared by the Student $t$-test. Correlations were evaluated by Pearson's correlation coefficient ( $r$ ). The level of significance was set at $\mathrm{P} \leq 0.05$ (32).

\section{Results and Discussion}

This is the first report on the role of the Th response in H. heilmannii gastric infection.

\section{Microbiological study}

Four weeks after inoculation, all mice infected with $H$. heilmannii-positive mucus showed tightly spiraled bacteria in carbolfuchsin-stained smears and in the histological sections, and also presented a positive urease test and were positive for $H$. heilmannii type 1 PCR. All tests carried out in all mice inoculated with $H$. heilmanniinegative mucus were negative.

No other Helicobacter species was detected by PCR and no spiraled bacterium grew in the medium used, regardless of whether the mucus from the source animal was $H$. heilmannii-positive or -negative.

The gastric sections of $H$. heilmanniipositive mice, irrespective of the animal strain, showed so many tightly spiraled bacteria that clusters of them were seen within every lumen of the glands. Even though this prevented the counting of individual bacteria, there was no apparent difference in bacterial density among groups. The urease tests applied to the gastric mucosa of all infected 
mouse strains also indicated the high degree of bacterial colonization by giving positive results within the first hour in all animals.

Since the degree of $H$. heilmannii colonization was similar in WT and IFN- $\gamma^{1-}$ C57BL/6 mice, no protective effect against $H$. heilmannii infection may be attributed to IFN- $\gamma$. Similar results were observed for $H$. pylori-infected WT and IFN- $\gamma^{-1-}$ C57BL/6 mice (9). The present results agree with the conclusions of Mohammadi et al. (6) who demonstrated that IFN- $\gamma$ neutralization with anti-IFN- $\gamma$ antibodies had no effect on the magnitude of $H$. felis colonization.

The gastric mucosa of $\mathrm{IL}_{-} 4^{-/-}$mice was as heavily colonized as the gastric mucosa of WT BALB/c mice, suggesting that IL-4 does not modulate $H$. heilmannii load. Similar results were obtained by Smythies et al. (9) in $H$. pylori-infected IL-4 ${ }^{-/}$mice. Conversely, Mohammadi et al. (33) showed that, in $H$. felis infection, the number of bacteria is greater in IL-4-/- than in WT C57BL/6 mice. In addition, Zavros et al. (34) showed that treatment with IL-4 reduced the $H$. felis load in a Th1 mouse model of Helicobacter infection. These differences may be due to differences between both the Helicobacter species and the host studied. Therefore, IL-4 may play a role in the host defense against $H$. felis colonization (33), but not against $H$. pylori (9) or $H$. heilmannii.

\section{Histological study}

The results of the histological evaluation are shown in Table 1.

\section{WT C57BL/6 and BALB/c mice}

The degree of PMN infiltrate in the antral mucosa was higher in $H$. heilmannii-positive than -negative WT C57BL/6 mice $(\mathrm{P}=$ 0.007), but no difference in MN levels was observed $(P=0.27)$. Conversely, no difference was observed in the degree of $\mathrm{MN}(\mathrm{P}=$ $0.58)$ or $\mathrm{PMN}$ cell infiltration $(\mathrm{P}=0.11)$ in the antral mucosa of $H$. heilmannii-positive and -negative WT BALB/c. When the oxyntic mucosa was studied, the levels of inflammatory cells were higher in $H$. heilmanniipositive than in $H$. heilmannii-negative WT C57BL/6 [MN $(\mathrm{P}=0.005)$ and $\mathrm{PMN}(\mathrm{P}=$ $0.007)]$ and WT BALB/c $[\mathrm{MN}(\mathrm{P}=0.01)]$ mice. When WT $H$. heilmannii-positive $\mathrm{C} 57 \mathrm{BL} / 6$ and $\mathrm{BALB} / \mathrm{c}$ mice were compared,

\begin{tabular}{|c|c|c|c|c|c|c|c|c|}
\hline & \multicolumn{4}{|c|}{ Antral mucosa } & \multicolumn{4}{|c|}{ Oxyntic mucosa } \\
\hline & \multicolumn{2}{|c|}{ Hh-negative } & \multicolumn{2}{|c|}{ Hh-positive } & \multicolumn{2}{|c|}{ Hh-negative } & \multicolumn{2}{|c|}{ Hh-positive } \\
\hline & $\mathrm{MN}$ & PMN & $\mathrm{MN}$ & PMN & MN & PMN & MN & PMN \\
\hline \multicolumn{9}{|l|}{ C57BL/6 } \\
\hline WT & $0(0-1)$ & $0(0-0)^{a}$ & $1(0-1)^{\mid}$ & $1(0-2)^{a, m}$ & $0.5(0-1)^{\mathrm{b}}$ & $0(0-1)^{\mathrm{C}}$ & $2(1-2)^{b, n}$ & $2(1-3)^{c, e, o}$ \\
\hline IFN- $\gamma^{/-}$ & $0(0-0)$ & $0(0-1)$ & $0(0-0)^{i, I}$ & $0(0-0)^{m}$ & $0(0-1)$ & $0(0-1)$ & $0(0-1)^{k, n}$ & $0(0-1)^{\mathrm{j}, \mathrm{O}}$ \\
\hline \multicolumn{9}{|l|}{ BALB/c } \\
\hline WT & $0(0-1)$ & $0(0-1)$ & $0.5(0-1)$ & $0(0-1)^{p}$ & $0(0-1)^{d}$ & $0(0-1)$ & $1.5(1-3)^{d}$ & $0(0-1)^{e, q}$ \\
\hline $\mathrm{IL}-4^{-/-}$ & $0(0-1)^{f}$ & $0(0-0)$ & $1(0-1)^{f, i}$ & $1(0-1)^{p}$ & $0(0-1)^{g, h}$ & $0(0-0)$ & $2(0-2)^{\mathrm{h}, \mathrm{k}}$ & $1(0-1)^{g, j, q}$ \\
\hline
\end{tabular}

Data are reported as median (range) of the score of inflammatory cell infiltration in the gastric mucosa $(0=$ absent, $1=$ mild, $2=$ moderate, and $3=$ marked). $\mathrm{Hh}=H$. heilmannii; $\mathrm{MN}=$ mononuclear cells; $\mathrm{PMN}=$ polymorphonuclear cells; WT $=$ wild type; ${ }^{-/-}=$knockout; IFN- $\gamma=$ interferon- $\gamma$; IL-4 $=$ interleukin-4. Equal superscript letters mean that differences between results were significant $(P \leq 0.05$, two-tailed Mann-Whitney U-test). 
the levels of PMN in the oxyntic mucosa were significantly higher in C57BL/6 animals $(P=0.001)$. No other differences were demonstrable $[\mathrm{PMN}(\mathrm{P}=0.21)$ and $\mathrm{MN}(\mathrm{P}=$ $0.58)$ in the antral mucosa and $\mathrm{MN}(\mathrm{P}=$ $0.52)$ in the oxyntic mucosa]. These data confirm our demonstration that the degree of the gastric inflammatory infiltration was higher in $H$. heilmannii-positive C57BL/6 than in BALB/c mice (35) and provide more in-depth information since we discriminated between PMN and MN cells. Also, in agreement with literature data, the levels of inflammatory cells in $H$. heilmannii-infected mice were not marked, ranging from absent (0) to moderate (2), as demonstrated in human gastric infection by $H$. heilmannii (16).

\section{Knockout C57BL/6 and BALB/c mice}

In the group of IFN- $\gamma^{1-}$ C57BL/6 mice, no difference was observed between $H$. heilmannii-positive and -negative animals [MN $(\mathrm{P}=1.0)$ and PMN $(\mathrm{P}=0.36)$ in the antral mucosa; $\mathrm{MN}(\mathrm{P}=0.91)$ and $\mathrm{PMN}(\mathrm{P}=$ $0.82)$ in the oxyntic mucosa].

In contrast to the results obtained for WT $\mathrm{BALB} / \mathrm{c}$ mice, in H. heilmannii-positive IL$4^{-/-}$animals, the degree of MN infiltration in the antral mucosa $(\mathrm{P}=0.05)$ and of $\mathrm{PMN}$ infiltration in the oxyntic mucosa $(\mathrm{P}=0.001)$ was significantly higher in $H$. heilmanniipositive than in the -negative animals. In contrast, similarly to WT BALB/c mice, the degree of PMN infiltration in the antrum did not differ between $H$. heilmannii-positive and -negative IL-4 ${ }^{-/-}$mice $(\mathrm{P}=0.4)$ and the degree of $\mathrm{MN}$ cell infiltration in the oxyntic mucosa was higher in the IL-4 $4^{-/} H$. heilmannii-positive than in the IL-4 ${ }^{-/-} H$. heilmannii-negative group $(\mathrm{P}=0.002)$.

When H. heilmannii-positive IL-4-/- and IFN- $\gamma^{-1}$ mice were compared, the scores of $\mathrm{MN}$ infiltration $(\mathrm{P}=0.03)$ in the antral mucosa and the scores of PMN (P=0.05) and $\mathrm{MN}(\mathrm{P}=0.001)$ infiltration in the oxyntic mucosa were significantly higher in BALB/ $\mathrm{c}$ than in C57BL/6 mice, whereas the degree of PMN infiltration in the antral mucosa was not significantly different $(P=0.39)$.

\section{Helicobacter heilmannii-positive knockout versus WT animals}

When $H$. heilmannii-positive WT and knockout mice were compared, differences were observed between IFN- $\gamma^{--}$and WT C57BL/6 [MN $(\mathrm{P}=0.02)$ and PMN $(\mathrm{P}=$ $0.007)$ in the antrum; $\mathrm{MN}(\mathrm{P}=0.002)$ and PMN ( $\mathrm{P}=0.01)$ in the oxyntic mucosa].

In the group of $H$. heilmannii-positive $\mathrm{BALB} / \mathrm{c}$ mice, the degree of PMN infiltration in the antral $(\mathrm{P}=0.03)$ and oxyntic mucosa $(\mathrm{P}=0.007)$, but not of $\mathrm{MN}$ infiltration in the antral $(\mathrm{P}=0.86)$ and oxyntic mucosa $(P=0.48)$ was significantly higher in the IL-4 ${ }^{-/-}$than in the WT group.

In agreement with the studies of D'Elios et al. (10) in H. pylori-positive patients and Mohammadi et al. (6) in H. felis-infected mice, our results also support the pathogenic role of Th1 cytokines and, in particular, of IFN- $\gamma$ in $H$. heilmannii-induced gastritis. First, the gastritis was more intense and not restricted to the corpus in $H$. heilmanniipositive WT C57BL/6 mice, which are prone to a predominantly Th1 response, than in $H$. heilmannii-positive WT BALB/c mice, which tend to exhibit Th2 polarization. Second, Zavros et al. (34) observed a significant increase of MN cells in the gastric mucosa of mice after 7 days of IFN- $\gamma$ infusion. Third, in agreement with the data of Sawai et al. (8) and Smythies et al. (9) who did not observe gastric inflammation in $\mathrm{H}$. pylori-infected IFN- $\gamma^{1-}$ mice and those of Mohammadi et al. (6) who observed a significant reduction of the gastric inflammation in $\mathrm{H}$. felis mice after anti-IFN treatment, in the present study, no gastric inflammation was seen in $H$. heilmannii-positive IFN- $\gamma^{1-}$ C57BL/6 mice. Therefore, as observed for $H$. pylori and $H$. felis infection, IFN- $\gamma$ seems to contribute to the severity of the gastritis associated with 


\section{H. heilmannii infection.}

There are conflicting results in the literature regarding the role of IL- 4 in mucosal inflammation. Chen et al. (7), while evaluating $H$. pylori-infected IL-4-/- and IL-4 transgenic (that produce higher levels of IL-4) C57BL/6J mice, did not observe a difference in the degree of gastric inflammation between these groups and concluded that IL-4 does not play a central role in the protection against gastric inflammation. Conversely, Zavros et al. (34) showed that IL-4 administration prevented the inflammatory response of the gastric mucosa of a Th1 background mice infected with $H$. felis. In addition, Smythies et al. (9) demonstrated a higher gastric inflammation in $H$. pylori-infected IL-4 ${ }^{-/}$than in WT mice, which was supposed to be due to an up-regulation of IFN$\gamma$ in the absence of IL-4. In agreement with Smythies et al. (9), we observed that IL-4 ${ }^{-/-}$ animals partially switched to a Th1 phenotype. The gastric inflammation scores were higher in infected IL-4-/- than in WT BALB/ c mice.

Thus, it seems that, in Helicobacter infection, the severity of gastric inflammation depends on IFN- $\gamma$ and some protective effect may be attributed to IL-4.

\section{Serum IL-4 and IFN- $\gamma$ concentration}

Irrespective of the infection, the levels of IL-4 were nearly undetectable in the IL-4-/groups. Although the serum levels of IL-4 were very low in the other groups, difference was observed between $H$. heilmannii-positive $(0.36 \pm 0.57 \mathrm{pg} / \mathrm{mL})$ and -negative $(1.20$ $\pm 0.59 \mathrm{pg} / \mathrm{mL}) \mathrm{WT}$ BALB $/ \mathrm{c}$ mice $(\mathrm{P}=0.03)$, as well as between $H$. heilmannii-negative WT BALB/c and WT C57BL/6 $(0.0 \pm 0.2$ $\mathrm{pg} / \mathrm{mL})$ animals $(\mathrm{P}=0.001)$. No other significant association was observed $[H$. heilmannii-positive $v s$-negative IFN- $\gamma^{-/-}$ C57BL/6 mice $(\mathrm{P}=0.14)$ and $H$. heilmanniinegative WT $v s$ IFN- $\gamma^{-/-}$C57BL/6 mice $(\mathrm{P}=$ 0.26)] (Figure 1). These results show that even in BALB/c mice, $H$. heilmannii infection elicits a Th1 response since the serum levels of IL-4 were significantly decreased in infected animals.

Serum IFN- $\gamma$ levels were undetectable in IFN- $\gamma^{-1-}$ C57BL/6 mice. Similar IFN- $\gamma$ levels were observed in $H$. heilmannii-positive $(11.03 \pm 3.07 \mathrm{pg} / \mathrm{mL})$ and H. heilmanniinegative $(11.07 \pm 3.5 \mathrm{pg} / \mathrm{mL})$ WT BALB/c mice $(\mathrm{P}=0.98)$, but IFN- $\gamma$ levels were higher in the H. heilmannii-positive $(38.16 \pm 10.5$ $\mathrm{pg} / \mathrm{mL})$ than -negative $(23.9 \pm 10.6 \mathrm{pg} / \mathrm{mL})$ WT C57BL/6 group ( $\mathrm{P}=0.04$; Figure 2), confirming the predominant Th1 profile of the C57BL/6 mouse strain.

In contrast to the results obtained for WT BALB/c mice, the serum levels of IFN- $\gamma$ were significantly higher in $H$. heilmanniipositive $(34.14 \pm 8.7 \mathrm{pg} / \mathrm{mL})$ than -negative $(21.2 \pm 9.6 \mathrm{pg} / \mathrm{mL}) \mathrm{IL}-4^{-/-} \mathrm{BALB} / \mathrm{c}$ mice $(\mathrm{P}$ $=0.02)$.

When WT and IL-4 ${ }^{-/}$BALB/c mice were compared, the serum IFN- $\gamma$ levels were significantly higher in both the $H$. heilmanniipositive $(\mathrm{P}=0.000)$ and -negative $(\mathrm{P}=0.05)$ IL-4-/- groups than in the H. heilmannii-posi-

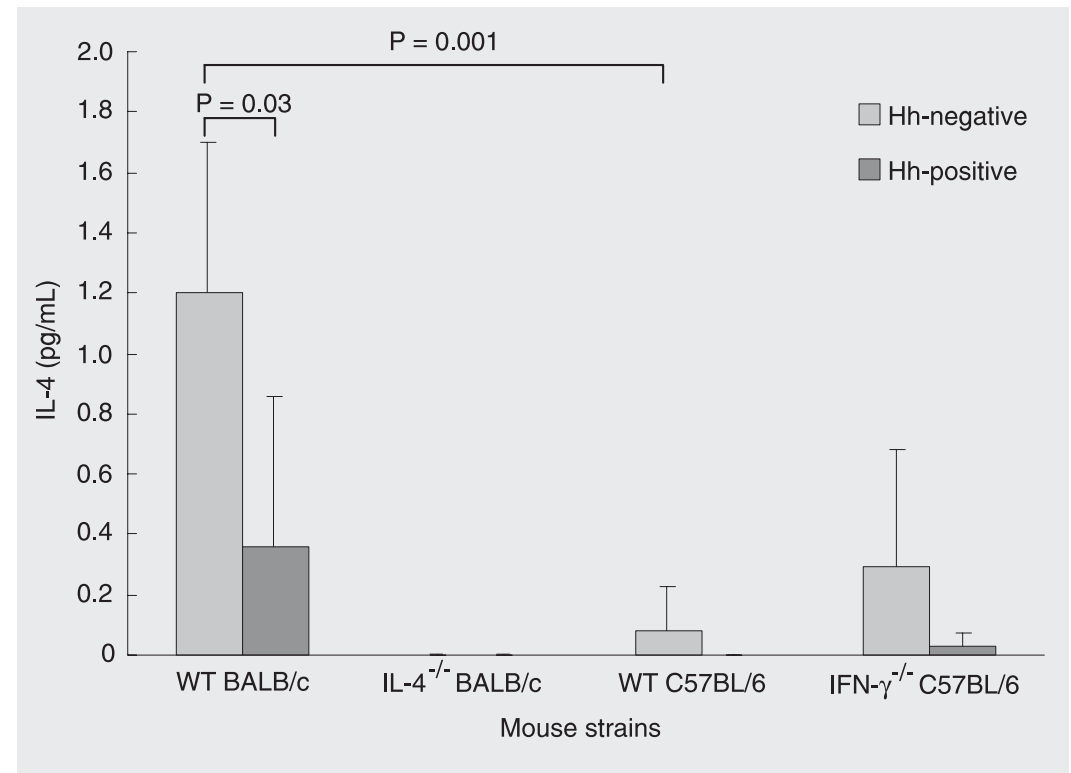

Figure 1. Serum IL-4 levels in Helicobacter heilmannii-negative and -positive wild-type and knockout BALB/c and C57BL/6 mice. $\mathrm{Hh}=H$. heilmannii; WT = wild type; ${ }^{-/-}=$knockout; IFN = interferon; IL-4 = interleukin-4. P values are shown only when the differences were significant (Student $t$-test). 
tive and -negative WT BALB/c groups. No differences between $H$. heilmannii-negative IL-4-/- and H. heilmannii-negative WTC57BL/ 6 mice $(\mathrm{P}=0.67)$ nor between $H$. heilmanniipositive IL-4 ${ }^{-/-}$and H. heilmannii-positive WT C57BL/6 mice $(\mathrm{P}=0.44)$ were seen. These results show that $H$. heilmannii infection leads to an increase of the Th1 cytokine IFN- $\gamma$.

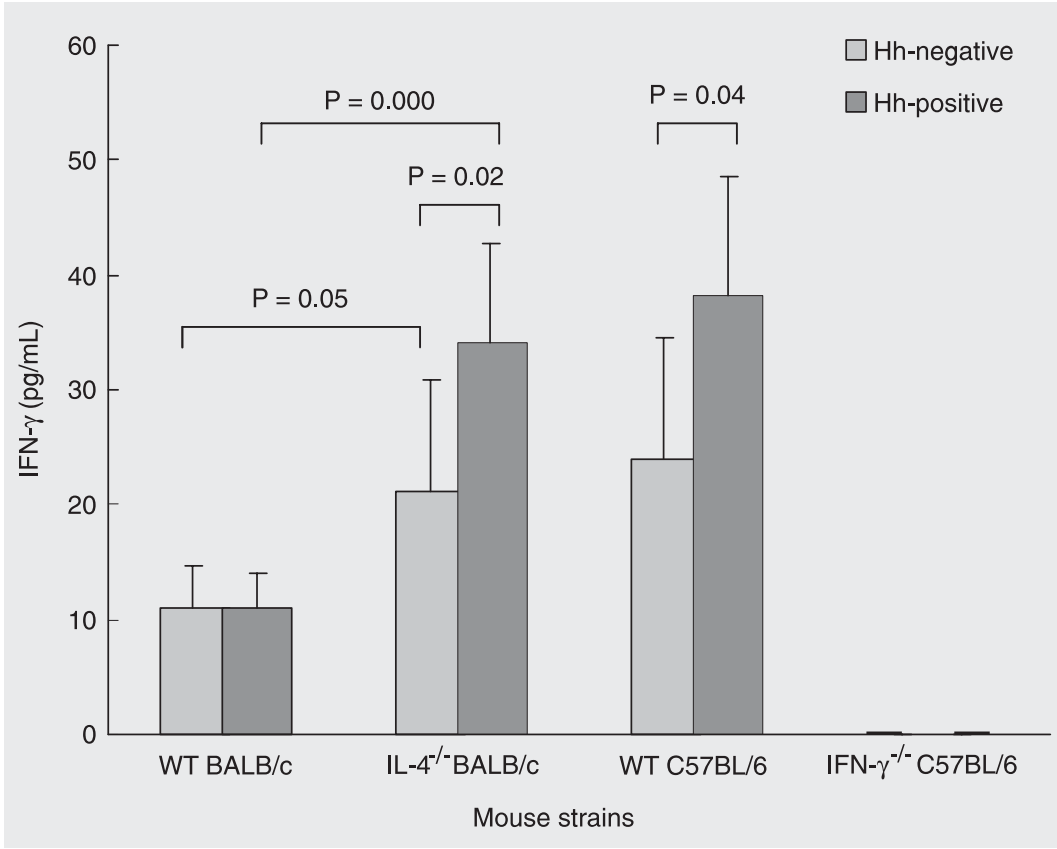

Figure 2. Serum IFN- $\gamma$ levels in Helicobacter heilmannii-negative and -positive wild-type and

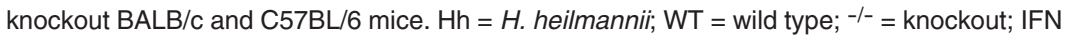
$=$ interferon; IL-4 = interleukin-4. $\mathrm{P}$ values are shown only when the differences were significant (Student $t$-test).
The serum concentrations of IFN- $\gamma$ positively correlated with the degree of $\mathrm{MN}(\mathrm{r}=$ $0.48, \mathrm{P}=0.001$ ) and $\mathrm{PMN}$ infiltration in the oxyntic mucosa $(r=0.46, P=0.01)$. A weak significant inverse correlation was detected between the levels of IL-4 and the degree of MN infiltration in the oxyntic mucosa $(r=$ $-0.27, \mathrm{P}=0.05)$. These results again show the relevance of IFN- $\gamma$ in inducing gastric inflammation especially in the corpus mucosa.

In conclusion, the results of the present study demonstrated that the inflammatory response of mice to $H$. heilmannii infection is similar to that seen in mice infected with other Helicobacter species, with IFN- $\gamma$ playing a pivotal role in gastric inflammation. We also demonstrated that the host background is a critical factor for the severity of the gastritis induced by H. heilmannii that is the basis for the development of severe diseases associated with Helicobacter infection.

\section{Acknowledgments}

The authors thank Dr. Luiz Vicente Rizzo, Department of Biochemistry and Immunology, USP, São Paulo, SP, Brazil, for providing $\mathrm{IL}-4^{-/-}$mice.

\section{References}

1. Logan RPH \& Walker MM (2001). ABC of the upper gastrointestinal tract: Epidemiology and diagnosis of Helicobacter pylori infection. British Medical Journal, 323: 920-922.

2. Cover RL \& Blaser MJ (1995). Helicobacter pylori: A bacterial cause of gastritis, peptic ulcer disease, and gastric cancer. ASM News, 61: 21-26.

3. Parsonnet J, Friedman GD, Vandersteen DP et al. (1991). Helicobacter pylori infection and the risk of gastric carcinoma. New England Journal of Medicine, 325: 1127-1131.

4. Isaacson PG (1994). Gastric lymphoma and Helicobacter pylori. New England Journal of Medicine, 330: 1310-1311.

5. Lee A (2000). Elimination of Helicobacter pylori is dependent on a Th2 response. In: Hunt RH \& Tytgat GNJ (Editors), Helicobacter pylori. Basic Mechanisms to Clinical Cure. Kluwer Academic Publishers, Dordrecht, The Netherlands.

6. Mohammadi M, Czinn S, Redline R et al. (1996). Helicobacter- specific cell-mediated immune responses display a predominant Th1 phenotype and promote a delayed-type hypersensitivity response in the stomachs of mice. Journal of Immunology, 156: 47294738 .

7. Chen W, Shu D \& Chadwick VS (1999). Helicobacter pylori infection in interleukin-4-deficient and transgenic mice. Scandinavian Journal of Gastroenterology, 34: 987-992.

8. Sawai N, Kita M, Kodama T et al. (1999). Role of gamma interferon in Helicobacter pylori-induced gastric inflammatory responses in a mouse model. Infection and Immunity, 67: 279-285.

9. Smythies LE, Waites KB, Lindsey JR et al. (2000). Helicobacter pylori-induced mucosal inflammation is Th1 mediated and exacerbated in IL-4, but not IFN- $\gamma$, gene deficient mice. Journal of Immunology, 165: 1022-1029.

10. D'Elios MM, Manghetti M, De Carli M et al. (1997). T helper 1 effector cells specific for Helicobacter pylori in the gastric antrum of 
patients with peptic ulcer disease. Journal of Immunology, 158: 962967.

11. Bamford KB, Fan X, Crowe SE et al. (1998). Lymphocytes in the human gastric mucosa during Helicobacter pylori have a $\mathrm{T}$ helper cell 1 phenotype. Gastroenterology, 114: 482-492.

12. Queiroz DMM, Cabral MMDA, Nogueira AMMF et al. (1990). Mixed gastric infection by Gastrospirillum hominis and Helicobacter pylori. Lancet, 336: 507-508.

13. Heilmann KL \& Borchard F (1991). Gastritis due to spiral shaped bacteria other than Helicobacter pylori: clinical, histological, and ultrastructural findings. Gut, 32: 137-140.

14. Ierardi E, Monno RA, Gentile A et al. (2001). Helicobacter heilmannii gastritis: a histological and immunohistochemical trait. Journal of Clinical Pathology, 54: 774-777.

15. Morgner A, Bayerdorffer E, Meining A et al. (1995). H. heilmannii and gastric cancer. Lancet, 346: 511-512.

16. Stolte M, Kroher G \& Meining A (1997). A comparison of Helicobacter pylori and $H$. heilmannii gastritis. A matched control study involving 404 patients. Scandinavian Journal of Gastroenterology, 32: 28-33.

17. Debongnie JC, Donnay M, Mairesse J et al. (1998). Gastric ulcers and Helicobacter heilmannii. European Journal of Gastroenterology and Hepatology, 10: 251-254.

18. Morgner A, Lehn N, Andersen CT et al. (2000). Helicobacter heilmannii-associated primary gastric low-grade MALT lymphoma: complete remission after curing the infection. Gastroenterology, 118: 821-828.

19. Meining A, Kroher $G$ \& Stolte $M$ (1998). Animal reservoirs in the transmission of Helicobacter heilmannii. Results of a questionnairebased study. Scandinavian Journal of Gastroenterology, 33: 795798.

20. Queiroz DMM, Rocha GA, Mendes EN et al. (1990). Spiral microorganism in the stomach of pigs. Veterinary Microbiology, 24: 199204.

21. Queiroz DMM, Rocha GA, Mendes EM et al. (1996). Association between Helicobacter and gastric ulcer disease of the pars esophagea in swine. Gastroenterology, 111: 19-27.

22. Moura SB, Queiroz DMM, Mendes EN et al. (1993). The inflammatory response of the gastric mucosa of mice experimentally infected with Gastrospirillum suis. Journal of Medical Microbiology, 39: 6468.

23. Mendes EN, Queiroz DMM, Moura SB et al. (1998). Mouse inocula- tion for the detection of non-cultivable gastric tightly spiraled bacteria. Brazilian Journal of Medical and Biological Research, 31: 373376.

24. Duval-Araujo I, Queiroz DMM, Magnago AGP et al. (2000). Increased gastric emptying induced by Helicobacter heilmannii type 1 infection in rats. Journal of Medical Microbiology, 49: 627-634.

25. Solnick JV, O'Rourke J, Lee A et al. (1993). An uncultured gastric spiral organism is a newly identified Helicobacter in humans. Journal of Infectious Diseases, 168: 379-385.

26. Nedrud JG, Mohammadi M, Blanchard T et al. (1998). Th1/Th2 lymphocyte responses in Helicobacter infections. In: Hunt $\mathrm{RH}$ \& Tytgat GNJ (Editors), Helicobacter pylori - Basic Mechanisms to Clinical Cure. Kluwer Academic Publishers, Dordrecht, The Netherlands, 101-109.

27. Houghton J \& Wang TC (2005). Helicobacter pylori and gastric cancer: a new paradigm for inflammation associated epithelial cancer. Gastroenterology, 128: 1567-1578.

28. Oliveira AG, Sanna MGP, Rocha GA et al. (2004). Helicobacter species in the intestinal mucosa of patients with ulcerative colitis. Journal of Clinical Microbiology, 42: 384-386.

29. Rocha GA, Queiroz DMM, Mendes EN et al. (1989). Simple carbolfuchsin staining for showing $C$. pylori and other bacteria in gastric mucosa. Journal of Clinical Pathology, 42: 1004-1005.

30. Queiroz DMM, Mendes EN \& Rocha GA (1987). Indicator medium for isolation of Campylobacter pylori. Journal of Clinical Microbiology, 25: 2378-2379.

31. Dixon MF, Genta RM, Yardley JH et al. (1996). Classification and grading of gastritis. The update Sydney system. American Journal of Surgical Pathology, 10: 1161-1181.

32. Snedecor GW \& Cochran WG (1989). Statistical Methods. 8th edn. lowa State University Press, Ames, IA, USA.

33. Mohammadi M, Nedrud J, Redline R et al. (1997). Murine CD4 T-cell response to Helicobacter infection: Th1 cells enhance gastritis and Th2 cells reduce bacterial load. Gastroenterology, 113: 1848-1857.

34. Zavros Y, Rathinavelu S, Kao JY et al. (2004). Treatment of Helicobacter gastritis with IL-4 requires somatostatin. Proceedings of the National Academy of Sciences, USA, 100: 12944-12949.

35. Cinque SMS, Queiroz DMM, Rocha GA et al. (2002). Cellular immune responses in Helicobacter heilmannii infection. Evaluation of the role of the host and the bacterium. Digestive Diseases and Sciences, 47: 823-830. 